\title{
KAISER, Reinhold, Die Burgunder
}

\section{Magali Coumert}

\section{OpenEdition}

\section{Journals}

\section{Édition électronique}

URL : http://journals.openedition.org/ifha/840

DOI : 10.4000/ifha. 840

ISSN : 2198-8943

Éditeur

IFRA - Institut franco-allemand (sciences historiques et sociales)

\section{Référence électronique}

Magali Coumert, «KAISER, Reinhold, Die Burgunder», Revue de I'IFHA [En ligne], Date de recension, mis en ligne le 01 janvier 2005, consulté le 22 septembre 2020. URL : http://journals.openedition.org/ifha/ 840 ; DOI : https://doi.org/10.4000/ifha.840

Ce document a été généré automatiquement le 22 septembre 2020.

(C)IFHA 


\title{
KAISER, Reinhold, Die Burgunder
}

\author{
Magali Coumert
}

Comme il le reconnait dans son introduction, l'entreprise de R.K. est ambitieuse puisqu'il cherche à présenter dans un petit format l'histoire des Burgondes du début du Ier au VIIIe s. de notre ère alors que l'époque de rédaction des histoires d'un peuple semble révolue : les sources sont dispersées, peu nombreuses, connues depuis longtemps, mais leur interprétation reste très controversée, tandis que l'archéologie, dont on espérait l'arbitrage, pose de nouvelles questions. Pourtant, l'ampleur du débat scientifique concernant la formation et l'installation des peuples barbares en Occident rend de telles synthèses de plus en plus nécessaires aux étudiants comme aux enseignants.

Rédigés dans une langue claire, les sept chapitres de l'ouvrage permettent une approche à la fois chronologique et thématique. Le premier chapitre s'efforce de retracer l'histoire des Burgondes avant leur installation sur les territoires de l'empire romain d'Occident, entre le Ier et le IVe $\mathrm{s}$. Le deuxième chapitre traite de la formation du premier royaume burgonde au bord du Rhin, entre 413 et 436, avant sa disparition face aux armées des Huns et d'Ætius, le troisième de l'installation des Burgondes en Sapaudia et de leur royaume jusqu'à sa soumission par les Francs en 534.

Les chapitres suivants sont divisés de façon thématique. Le chapitre IV concerne l'évaluation du nombre des Burgondes, du mode de partage, fiscal ou réel, qui permit leur installation ainsi que l'interprétation des traces archéologiques et linguistiques laissées par celle-ci. Le chapitre suivant est consacré aux structures internes du royaume burgonde, notamment sa législation. Le sixième chapitre traite du rôle des Églises au sein de celui-ci, depuis la conversion au christianisme, puis la coexistence de l'arianisme et de l'orthodoxie doctrinale et enfin les tentatives de création d'une Église indépendante, appuyée sur d'importants monastères. Le dernier chapitre s'interroge sur la persistance d'une identité burgonde, après la chute de leur royaume indépendant. Reprise par la famille mérovingienne au VIe s., l'identité burgonde se transforma en identité régionale au cours des deux siècles suivants. Limitée aux régions situées à l'ouest de la Saône par le partage de Verdun, ses fondements historiques furent rappelés dans le chant des Gibichung/ Nibelung composé vers 1200. 
La synthèse de R.K. s'appuie sur de nombreuses cartes qui n'hésitent pas à exposer les différences entre les hypothèses des spécialistes, ainsi que sur une bibliographie rappelant la diversité des sources utilisées et comportant de nombreux articles récents. Certains débats y sont clairement exposés, par exemple concernant la présentation des rois burgondes par Ammien Marcellin ou l'évolution religieuse des Burgondes, mais d'autres controverses récentes ne sont pas prises en compte, comme à propos des variations du sentiment d'appartenance ethnique ou de l'interprétation en termes ethniques des données archéologiques. Cette synthèse est ainsi utile pour une première approche de l'histoire burgonde, mais ne saurait remplacer la consultation d'ouvrages plus détaillés.

Magali COUMERT (Université Paris X-Nanterre) 